
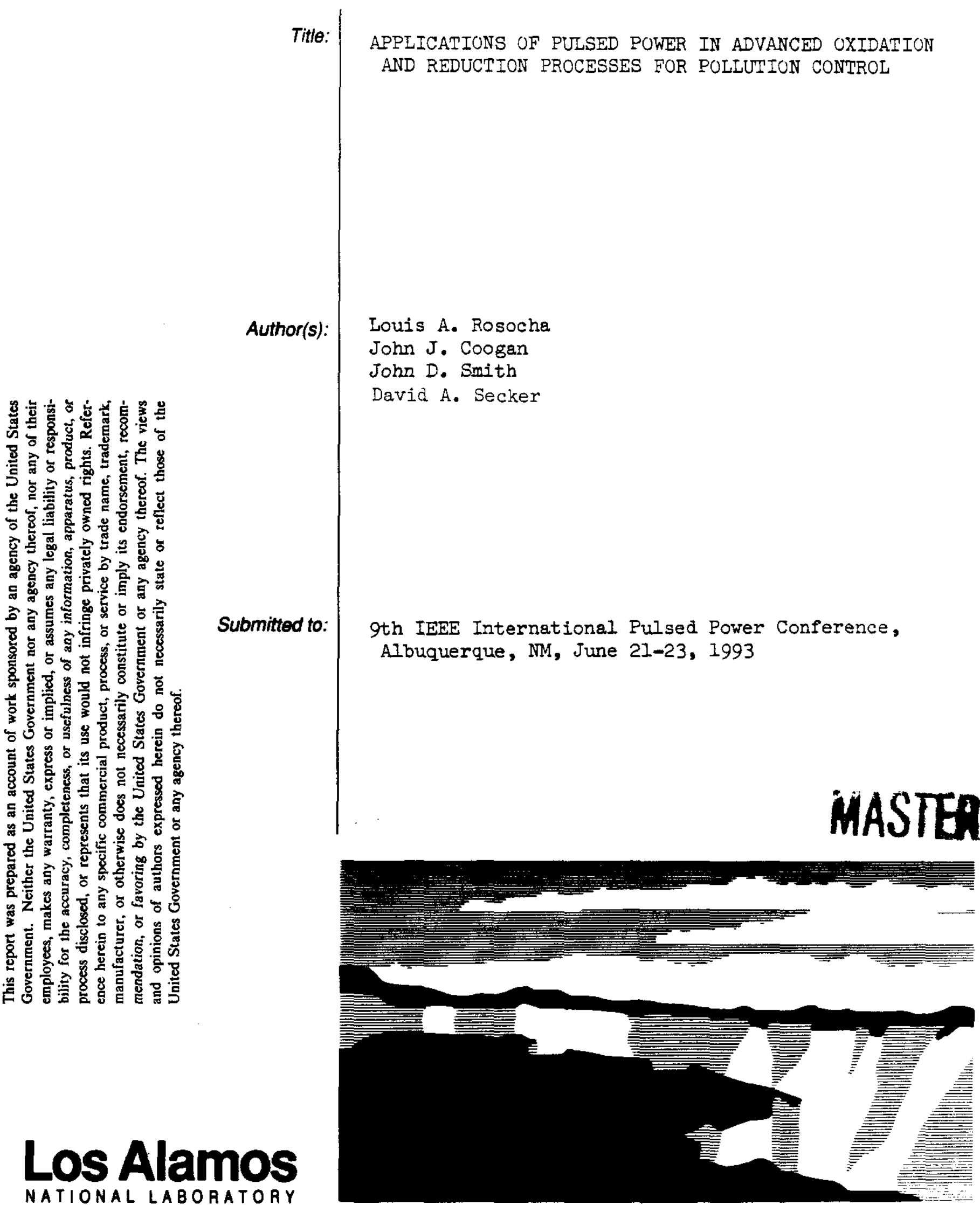


\title{
APPLICATIONS OF PULSED POWER IN ADVANCED OXIDATION AND REDUCTION PROCESSES FOR POLLUTION CONTROL
}

\author{
L. A. Rosocha, J. J. Coogan, D. A. Secker, and J. D. Smith \\ Los Alamos National Laboratory \\ P.O. Box 1663, MS J564 \\ Los Alamos, NM 87545
}

\section{Abstract}

A growing social awareness of the adverse impact of pollutants on our environment and the promulgation of environmental laws and regulations has recently stimulated the development of technologies for pollution abatement and hazardous waste destruc tion. Pulsed power shows strong promise for contributing to the development of innovative technologies aimed at these applications At Los Alamos we are engaged in two projects which apply pulsed power technology to the environment: the use of relativistic electron beams and nonequilibrium plasmas for the destruction of hazardous organic compounds in aqueous-based and gaseous-based media, respectively. Electron bearns and nonequilibrium plasmas have also been applied to the treatment of flue gases such as $\mathrm{SO}_{\mathrm{x}}$ and $\mathrm{NO}_{\mathrm{x}}$ by other researchers. In this paper, we will describe our electron-beam and plasma experiments carried out on hazardous waste destruction. Additionally, we will describe the scaling of electron-beam and nonequilibrium plasma systems to industrial sizes, including discussions of electron accelerator architecture, comparison of continuous-duty versus repetitively pulsed accelerators, plasma-discharge modulators, and needed pulsed power technology development.

\section{Introduction}

The contamination of water and air with hazardous chemicals is presently a concem of intemational scope. In the United States, the Department of Energy (DOE), the Department of Defense (DoD), and private industry are facing increasing problems and economic concerns with the management of hazardous wastes. To prevent toxic substances from entering and spreading through the environment, and to meet increasingly stringent regulations (e.g., Clean Water Act and Clean Air Act Amendment), more effective methods of destroying hazardous chemical substances are being developed. A promising class of methods is referred to as advanced oxidation and reduction processes (AOPs and ARPs). The AOPs/ARPs that we use are nonthermal processes in which electrical energy, rather than thermal energy, is used to create large quantities of highly reactive (oxidative and/or reductive) free radicals. These radicals subsequently react with hazardous organic chemicals, converting them to nonhazardous substances ( $\mathrm{CO}_{2}, \mathrm{H}_{2} \mathrm{O}$, and mineralized compounds). Nonthermal processes allow for the promotion of desired chemistry without the large enthalpy losses and potential augmentation of waste streams (e.g., with greenhouse gases) characteristic of thermal processes. Our AOPs/ARPs apply relativistic electron beams and nonequilibrium plasmas to the destruction of aqueous-based and gaseous-based hazardous organic compounds, respectively. We are focusing on the strengths of each technology in optimizing it for a particular waste stream, but because the chemistry and pulsed power of our chosen technologies have much in common, developing one method often aids development of another. From a pulsed power viewpoint, there is a connection between the optimal formation of free radicals and the properties of the electrical driver. We have explored this issue for electron beams and nonequilibrium plasmas and will discuss it in this paper.

\section{Electron-Beam Treatment of Aqueous-Based Hazardous Wastes}

\section{Background and General Results}

High energy electron beams have been shown to be effective for the removal of hazardous organic contaminants in aqueous media and show great potential as a generally applicable technology for disinfection and sterilization [1,2]. The process of electron-beam irradiation is best understood in aqueous solutions in which sizable quantities of free radicals $\mathrm{e}_{\mathrm{ay}}{ }^{-}, \mathrm{H}$. and $\mathrm{OH}$. ds welf as the more stable oxidant $\mathrm{H}_{2} \mathrm{O}_{2}$ are produced. These highly reactive species react with organic contaminants to produce ubstances that are not hazardous $\left(\mathrm{CO}_{2}, \mathrm{H}_{2} \mathrm{O}\right.$, and mineral salts or aciuss). E-beam technology also appears to be economically competitive with existing methods [3].

We have contigured an existing electron accelerator for technology evaluation studies and demonstrated the destruction of iwo characteristic hazardous organic compounds. The test hed isee Th 4 operates in single-pulse mode $165-n$ s pulse widthi. typically producing beam voltages of $1.5-2.0 \mathrm{MeV}$ and dowes in the range $47 \mathrm{Mrad}\left(40 \times 10^{3}-70 \times 10^{3} \mathrm{~Gy}\right)$. To hetter understand the waste removal process and explore e-beam treatment cialing issues. we have employed a computer-based chemical kinetics model io predict the expected removal efficiency and to compare standiard electrostatic accelerators to pulsed accelerators in terms of reactive free radical production [4]. Typical measured single-pulse destructions for trichloroethylene (TCE) are in the range $9(0-95 \%$, in good agreement with our model. It should be pointed out that this short. single-pulse destruction is much less efficient than other dose profiles (e.g., continuous-duty profile) because of the radical-radical recombination phenomenon discussed further below. In addition, we have implemented a laser absorption system for measuring aqueous electron concentrations produced by the elcctron beim.

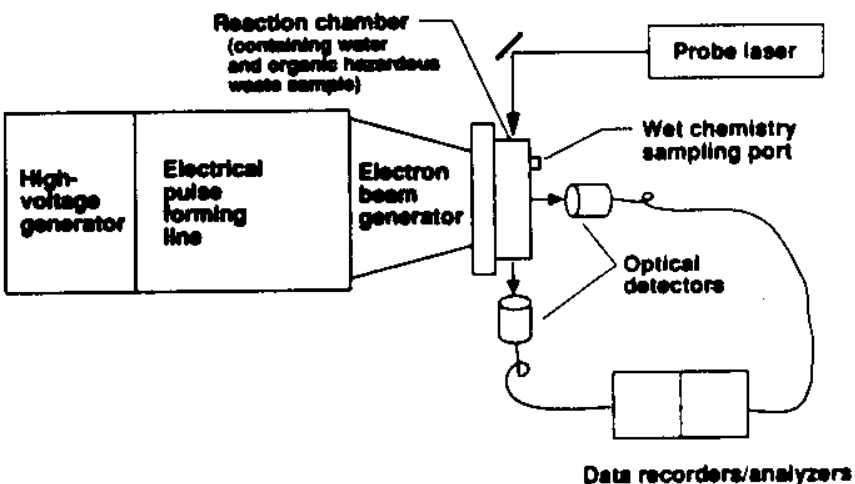

Fig. 1. Schematic diagram of the Los Alumos electron-heam test bed for hazardous waste treatment.

\section{Scaling Studies \& Accelerator Architectures}

Conventional electrostatic electron accelerator equipment has generally been employed for high average power irradiation applications, while single-pulse accelerators have been utilized for high dose rate research. Recent technology developments [5.6] have lead to a new generation of pulsed linear induction accelerators driven hy solid-state electrical power conditioning elements r see Fig. 2). These are considered to be less expensive per unit delivered e-beam dose, physically smaller, modular, and more reliable than conventional electrostatic accelerators. It is speculated that these repetitively pulsed accelerators will produce better chemicul destriction as well. although this remains to demonstrated. At present. we have found 
Type $1-1 / 2$ spoce ONLY; Keep

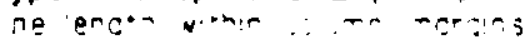

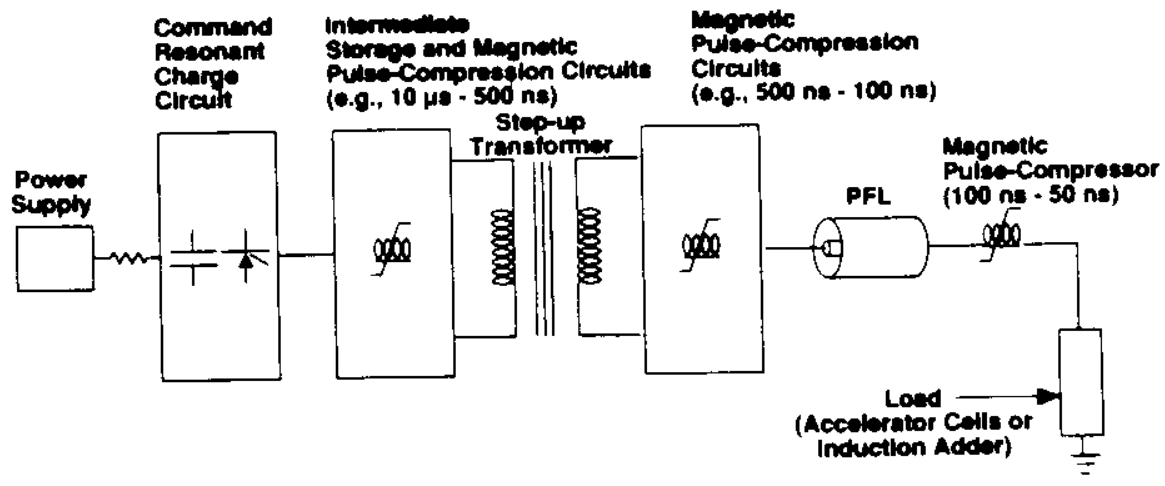

Fig. 2. Schematic diagram of compact high average power solid-state modulator for driving advanced pulsed linear induction accelerators.

no data comparing waste desiruction by repeatively pulsed accelerators with that of conventional electrostatic accelerators. Once demonstrated, these new accelerators would allow a considerable simplification in treatment plant architecture.

Resolving questions about how one chooses a particular accelerator system architecture for overall maximum effectiveness requires an understanding of the basic removal processes and a combination of experimental tesing and kinetic modeling. At Los Alamos, the e-beam laboratory was set up to study the irradiation process using short ( $-65 \mathrm{~ns})$, high current pulses. To better understand the waste removal process and e-beam machine scaling, we have also employed a computer-based chemical kinetics model to relate destruction effectiveness to electron-beam dose profiles and electron-beam machine parameters, and to make comparisons with experimental data.

The first of these studies examined radical production with very short $(<100 \mathrm{~ns})$, high dose-rate pulses in pure water. We examined the production and recombination of these transient species as a function of dose parameters. Our goal was to maximize the average free radical concentrations over a given period of time, for a given dose, by varying dose rate, pulse duration, and pulse repetition rate, thus providing greatest destruction potential. Our preliminary simulation results show that low dose rates have advantages over higher dose rates for the efficient production of radicals. This is apparently due to nonlinearities within the water model that favor radical recombination over radical production at higher dose rates. With TCE or other pollutants present, it has been postulated (although not demonstrated) that the formation of radical adducts and their subsequent reactions will produce favorable nonlinear effects that possibly make the pulsed case more advantageous in terms of chemical efficiency.

Our scaling studies have also explored the optimal dose profiles for free radical production and waste destruction using both conventional continuous-duty accelerators and repetitively pulsed accelerators. Although the computer modeling shows that a continuously applied dosage is more efficient in destroying waste than the same amount of single-pulse dosage, the modeling does show that a repetitively pulsed machine can produce similar radical concentrations to those of a DC machine when pulsed at high pulsed repetition rates (e.g., $10 \mathrm{kHz}$ ). This is shown in which gives running averages of radical concentrations for both DC and reperitively pulsed dose profiles.

Tables 1 and 2 give TCE and $\mathrm{CCl}_{4}$ destruction $\mathrm{Vs}$ dose for various methods of dose application. The initial concentrations and applied doses are chosen in an attempt to reproduce results from another facility. Four cases are examined for both compounds:

Single 100 -ns pulse,

$100-\mathrm{ns}, 1-\mathrm{kHz}$ repetition rate pulse train,

$100-\mathrm{ns}, 10-\mathrm{kHz}$ repetition rate pulse train, and

DC irradiation.
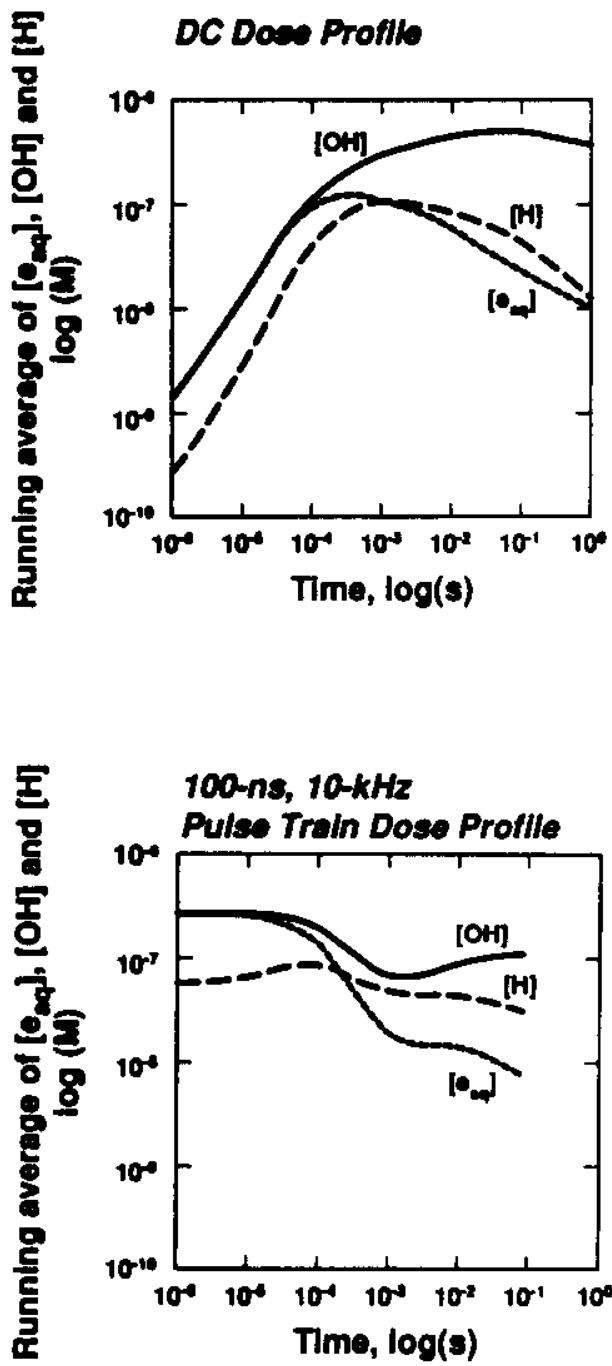

Fig. 3. Plots of nuning averages of free radical concentrations for $D C$ and repetitive short pulse dose profiles. 
Table 1. TCE Destruction Calculated for Different Doses and Methods of Application

\begin{tabular}{|l|c|c|}
\hline Dose Method & Fractional Destruction (\%) \\
\hline & $\begin{array}{c}\text { 100-krad } \\
\text { dose }\end{array}$ & $\begin{array}{c}\text { T50-krad } \\
\text { dose }\end{array}$ \\
\hline 100-ns pulse & 37.5 & 46.1 \\
\hline 1-kHz pulse train & 68.0 & 92.2 \\
\hline 10-kHz pulse train & 68.8 & 95.9 \\
\hline DC & 69.4 & 96.8 \\
\hline
\end{tabular}

Notes: initial TCE concentration is $100 \mathrm{ppm}$; residence time is $0.1 \mathrm{sec}$.

Table 2. $\mathrm{CCl}_{4}$ Destruction Calculated for Different Doses and Methods of Application

\begin{tabular}{|l|c|c|}
\hline Dose Method & \multicolumn{2}{|c|}{ Fractional Destruction (\%) } \\
\hline & 50-krad dose & $\begin{array}{c}\text { 100-krad } \\
\text { dose }\end{array}$ \\
\hline 100-ns pulse & 29.3 & 34.1 \\
\hline $1-\mathrm{kHz}$ pulse train & 77.9 & 91.2 \\
\hline $10-\mathrm{kHz}$ pulse train & 81.2 & 94.1 \\
\hline DC & 81.8 & 94.9 \\
\hline
\end{tabular}

Notes: initial $\mathrm{CCl}_{4}$ concentration is $10 \mathrm{ppm}$; residence time is $0.1 \mathrm{sec}$.

In terms of destruction effectiveness, both the $1-\mathrm{kHz}$ and $10-\mathrm{kHz}$ pulse trains approach the DC-case fractional removal.

\section{Nonequilibrium Plasma Treament of} Gaseous-Based Hazardous Wastes

\section{Background and Experimental Results}

Nonthermal plasma chemical reactor work at Los Alamos has demonstrated the potential for removing hazardous organics to very low levels (approaching tens of ppb to several ppb) by freeradical "cold combustion" [7]. We employ nonthermal plasmas created by silent electrical discharges in the gas stream - arrested transient electrical discharge streamers, generated with a dielectric barrier configuration (secat The plasma produces energetic electrons (typical energies of 1-10 eV), which in tum generate copious quantities of highly reactive free radicals. The electrons are selectively heated, which results in an efficient transfer of electrical energy to desirable chemical reactions at near-ambient temperatures and pressures. Although the volume of the microdischarges is quite small, an extremely large number of them are statistically spread out in space and time, resulting in a large effective processing volume. The free radicals, primarily atomic oxygen $O\left({ }^{3} \mathrm{P}\right)$ and hydroxyl $\mathrm{OH}$, oxidize organic compounds to nonhazardous, easily managed compounds such as $\mathrm{H}_{2} \mathrm{O}, \mathrm{CO}_{2}$, and $\mathrm{HCl}$. The potential of nonthermal plasma processing (dielectric bartier, corona, pulsed corona, etc.) is actively being pursued through a variety of international research efforts directed at flue gases ( $\mathrm{SO}_{\mathrm{x}}$ and $\mathrm{NO}_{\mathrm{x}}$ ) and hazardous organics (volatile organic compounds - VÔCs).

We have focused on the silent discharge, which is sometimes called silent discharge plasma (SDP) because of the potential for high energy efficiency, large volume processing, scientific and technological maturity, and scalability (all typical of commercial ozone generation). Silent discharges are a natural means of creating plasmas which are potentially close to the optimal reduced electric field $\mathrm{E} / \mathrm{N}$ for the production of oxidizing species. They also operate at high pressures (atmospheric and above), resulting in high rates of chemical reaction and large reactor throughput.

We have employed both single-barrier and double-barrier reactors in our experiments. A typical planar cell has approximate dimensions of $71-\mathrm{cm}$ length, $18-\mathrm{cm}$ width, and $2.5-\mathrm{mm}$ gap, giving a mean discharge area of $1236 \mathrm{~cm}^{2}$ and an active discharge volume of $310 \mathrm{~cm}^{3}$.
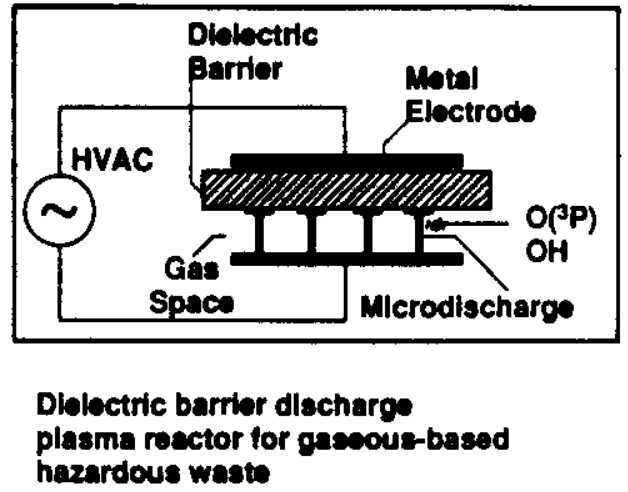

Fig. 4. Schematic drawing of representative dielectric harrier discharge configuration. Single or double barriers are rvpically emploved in either planar (shoun) or cylindrical geometry.

Our principal electrical power supply is a series inverter. which switches charged capacitors through a high-quality pulse transformer by means of high-power thyristors ( see Fig. 5). This unit presently supplies nearly $4 \mathrm{~kW}$ of power at voltage pulse repet1tion frequencies up to $4.5 \mathrm{kHz}$. Using this power supply and the planar cell, representative operating conditions for the TCE tests were a flow rate of $10 \mathrm{std} \mathrm{lit} / \mathrm{min}$ and an average power of $200 \mathrm{~W}$ This gives an average electrical energy density in the discharge of $1.2 \mathrm{~J} / \mathrm{cm}^{3}$, while the average area power density is approximately $0.16 \mathrm{~W} / \mathrm{cm}^{2}$. Higher flow rates have now been achieved.

We have demonstrated prototype-scale SDP destruction of aliphatic hydrocarbons, CFCs (chloro-fluorocarbons), TCE (trichloroethylene), and $\mathrm{CCl}_{4}$. Gas flows of $10-20 \mathrm{std} \mathrm{lit/min} \mathrm{and}$ TCE concentrations in the range $650-1,000 \mathrm{ppm}$ have been tvpical influent parameters for our tests. Summary data is given in Fis. which plots the destruction efficiency for $\mathrm{TCE}$ and $\mathrm{CCl}_{4}$ versus energy density for both wet ( $\sim 1 \%$ water vapor) and dry mixtures.
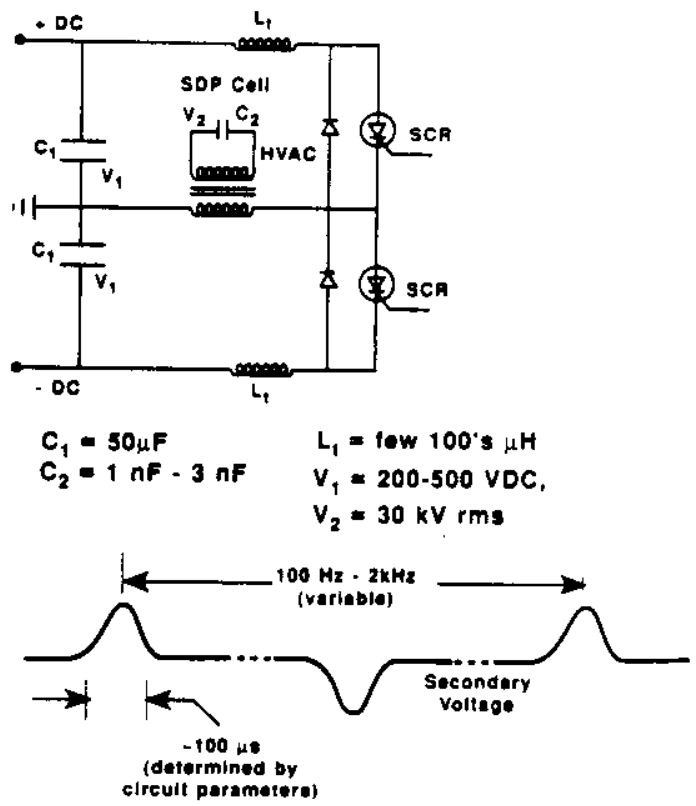

Fig. 5. Circuit schematic and representative voltage naveform for the high-voltage, variable-frequency series inverter driver used in most of our experiments. Typical cell peak voltages are in the range $25.35 \mathrm{kV}$. The frequency can be suried over a range of approximately $10 \mathrm{~Hz}-3500 \mathrm{~Hz}$. 


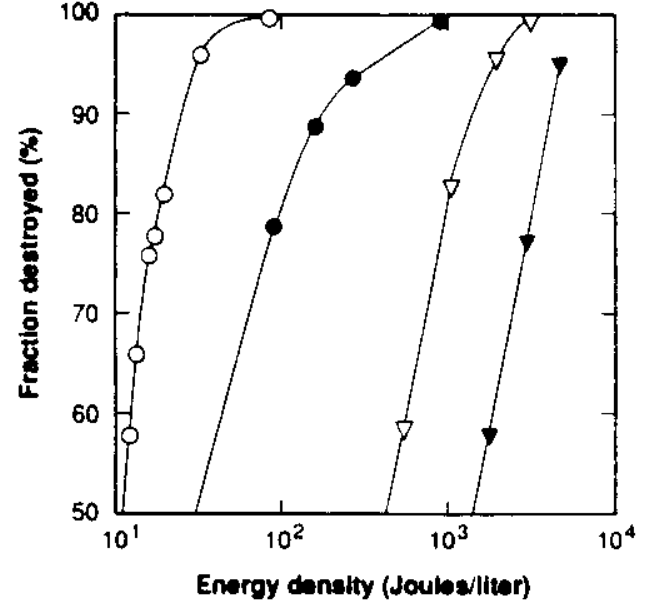

Fig. 6. Plots of $\mathrm{TCE}$ and $\mathrm{CCl}_{4}$ removal versus energy density showing summary data for both wet and dry gas mixtures. The carrier gas was $80 \%$ Ar. $20 \% \mathrm{O}_{2}$, order $500-100 \mathrm{ppm}$ chlorocarbon, and $1.2 \%$ water vapor (if wet).

At the water vapor concentrations employed in the illustrated results, the dry mixture gives greater removal for both TCE and $\mathrm{CCl}_{4}$, which may be a consequence of $\mathrm{Cl}$ chain reactions in the dry case.

\section{Silent Discharge Plasma Reactor Scaling}

To scale SDP reactors, the fractional removal is related to the plasma energy density (average power $\langle P\rangle$, divided by gas flow rate $Q$ ). For our wet experiments, doubling the reactor power or halving the flow rate will result in the same destruction. For dry mixtures, which may be dominated by chain reactions, this scaling parameter does not necessarily apply. A figure of merit for removal is essentially determined by the energy delivered to the plasma per hazardous molecule removed from the gas stream. A convenient unit for the figure of merit is the number of kilowatt-hours required to remove a kilogram of hazardous compound (i.e., $\mathrm{kW}-\mathrm{hr} / \mathrm{kg}$ ). From the data presented previously, the removal figures of merit are determined to be approximately $12 \mathrm{~kW}-\mathrm{hr} / \mathrm{kg}$ for $90 \%$ removal of TCE, $84 \mathrm{~kW}-\mathrm{hr} / \mathrm{kg}$ for $>99 \%$ removal of TCE $(650-1,000 \mathrm{ppm}$ to $\sim 100 \mathrm{ppb}$ ) and $270 \mathrm{~kW} \cdot \mathrm{hr} / \mathrm{kg}$ for $90 \%$ removal of $\mathrm{CCl}_{4}$. Another way to express this is in terms of the amount of energy required to destroy the contaminant level by a factor of 10 . We have named this factor the 9-factor, since if three 9's destruction (i.e., 0.999 or $99.9 \%$ destroyed) is required, three times the 9-factor must be applied to the waste stream. This factor has the units of J/lit (or $\mathrm{J} / \mathrm{cm}^{3}$ ). Preliminary values of the 9 -factor for TCE are: $25.3 \mathrm{~J} / \mathrm{it}$ $\left(0.0253 \mathrm{~J} / \mathrm{cm}^{3}\right) \mathrm{dry}$, and $75 \mathrm{~J} /$ hit $\left(0.075 \mathrm{~J} / \mathrm{cm}^{3}\right)$ wet. The advantage of this parameter is that it is a single value and, unlike $\mathrm{kW}-\mathrm{hr} / \mathrm{kg}$, is valid regardless of the initial concentration of waste.

Using the 9-factor, scaling calculations are simplified. For example, the removal of TCE under wet conditions can be scaled as shown in plot of degree of destruction versus gas flow rate for one, two, and four cells.

The scalability of SDP reactors and associated power supplies is influenced by the desired gas flow rate and the concentration of hazardous compounds to be treated. Consideration of mechanical constraints, single-point failures, and successful architecrures used in the commercial ozone generation industry has led us to choose modularization as a preferred approach. Currently, we are considering scalable modules consisting of combinations of several smaller modules (see fun this design will quickly enable a scale up of gas flow rates by factors of 10 to 100 . For more corrosive compounds double barriers can be used so that there is no contact between the corrosive gas mixture and any metal surface.

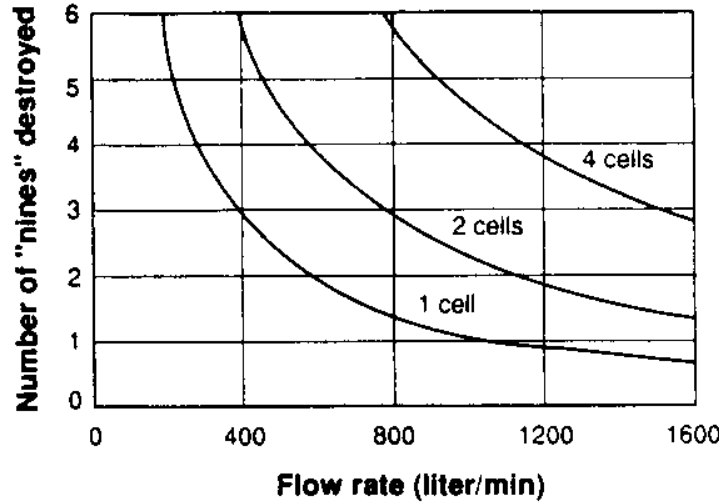

Fig. 7. Scaling plot for the destruction of TCE under humid conditions. The number of nines destroyed is plotted versus the flow rate for one, two and four plasma cells.

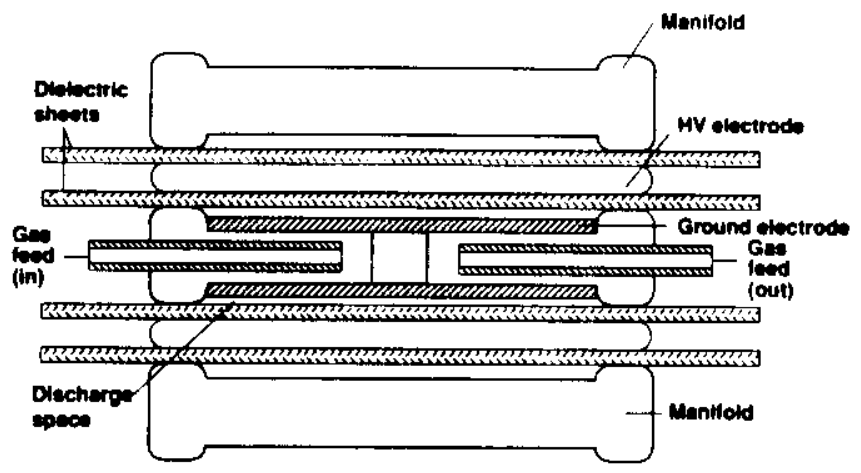

Fig. 8. Schematic diagram of stacked module containing four planar SDP cells, operated in parallel.

\section{Eunure Directions}

Additional factors can influence the production of free radicals in nonequilibrium plasmas. Investigations worldwide are in progress on the effects of electrical driver pulse width and rise time, electrical drive circuit coupling to plasma cells, and the role of UV light in the plasma chemisury and discharge processes. We speculate that, if free radical utilization is dominated by radical-radical recombination (which may happen in microdischarges), a fast rise time, homogeneous discharge may be more efficient in destroying contaminants. This is yet to be demonstrated. We will soon start experiments on the effect of rise time on SDP processing in our laboratory at Los Alamos.

\section{Summary and Conclusions}

We have examined free radical production in aqueous solutions irradiated with electron beams. Our goal was to provide the greatest destruction potential by varying dose rate, pulse duration, and pulse repetition rate. When radical-radical recombination dominates, low dose rates are more advantageous than high dose rates. However, a suitable application of repetitive short-duration pulses (e.g., $100 \mathrm{~ns}$ ) gives radical concentrations and fractional removals similar to a DC applied dose. New high-average-power pulsed linear induction accelerators are judged to be advantageous to conventional electrostatic accelerators for waste treatment because of relaxed requirements on high voltage isolation, ease of scaling to high power, modularity, smaller physical size, and broad range of power control. 
Nonthermal discharge plasmas also show promise for the removal of VOCs and other air toxics such as $\mathrm{SO}_{x}$ and $\mathrm{NO}_{\mathrm{x}}$ in flue gas. Removal figures of merit have been established and reactors have been scaled to energy density levels that will permit industrial service. Basic understanding of the plasma chemistry has evoived to the point where trends and equipment scaling can be predicted with reasonable confidence [8]. Because the process can simultaneously remove different types of pollutants, it is particularly attractive for future environmental applications.

\section{References}

[1] W.J. Cooper, M.G. Nickelsen, T.D. Waite, and C.N. Kurucz, "High Energy Electron Beam Irradiation: An Advanced Oxidation Ptocess for the Treatment of Aqueous Based Organic Hazardous Wastes," in Proceedings of the Symp. on Advanced Oxidation Processes for the Treatment of Contaminated Water and Air, Toronto, Canada (June 1990).

[2] L.A. Rosocha, D.A. Secker, and J.D. Smith, "Electron-Beam Technology for Detoxification and Sterilization of AqueousBased Hazardous and Biological Wastes," EPRI/NSF Symposium on Environmental Applications Advanced Oxidation Technologies, San Francisco, California, February 1993.

[3] R.B. Kidman and K.S. Tsuji, "Preliminary Cost Comparison of Advanced Oxidation Processes," Los Alamos National Laboratory report, LA-12221-MS (June 1992).

[4] L.A. Rosocha. D.A. Secker and J.D. Smith, "Kinetic Modeling of TCE and Carbon Tetrachloride Removal from Water by Electron-Beam Irradiation," American Chemical Society / \& EC Special Symposium on Emerging Technologies in Hazardous Waste Management, Atlanta, Georgia (September 1992).

[5] J.H. Jacob, "Reliable Low Cost Induction Accelerator System for Treatment of Industrial and Municipal Wastewater," private communication, Science Research Laboratory, Sommerville, Massachusetts (August 1991).

[6] H.C. Harjes, K.J. Penn, K.W. Reed, C.R. McClenahan, G.B. Laderach, R.W. Wavrik, J. Adcock, M. Butler, G.A. Mann, L. Martinez, F.A. Morgan, G.J. Weber, and E.L. Neau, "Status of the Repetitive High Energy Pulsed Power Project," in Proceedings of the 8th IEEE Pulsed Power Conference (June 1991).

[7] L.A. Rosocha, G.K. Anderson, L.A. Bechtold, J.J. Coogan, H.G. Heck, M. Kang, W.H. McCulla, R.A. Tennant, and P.J. Wantuck, "Treatment of Hazardous Organic Wastes Using Silent Discharge Plasmas," in Proceedings of NATO Advanced Research Workshop on Nonthermal Plasma Techniques for Pollution Control, Cambridge, England, September. $21-25,1992$ (to be published by Springer-Verlag).

[8] L.A. Rosocha, "Nonthermal Discharge Session Summary," and other papers, EPRI/NSF Symposium on Environmental Applications Advanced Oxidation Technologies, San Francisco, California, February 1993. 